\title{
Ratcheting wear of a cobalt-chromium alloy during reciprocated self-mated dry sliding
}

\author{
P.S.G Cross ${ }^{*}$, G. Limbert ${ }^{1}$, Dave Stewart ${ }^{2}$, R.J.K. Wood ${ }^{1}$ \\ ${ }^{1}$ University of Southampton, Southampton, Hampshire, UK \\ ${ }^{2}$ Rolls-Royce plc., Derby, UK
}

\begin{abstract}
Cobalt-chromium alloys find usage in environments where reliable wear and friction properties are required. However, the sliding wear generated presents significant health risks in nuclear and medical applications. Thus, there is great motivation to develop cobalt-free alternatives. These alloys are known to undergo several physical changes at the interface during dry sliding, sensitive to the loading conditions and environment. Due to these physical changes, the wear behaviour of the alloy is modified, which linear Archard-like models do not capture. To better understand the wear performance a cobalt-chromium alloy in-situ, and to aid their replacement, a mechanistic model of wear would be ideal. To understand what physics requires modelling, in order to capture the wear behaviour in response to the loading conditions, a systematic experimental study was performed for a cobalt-chromium hard-facing alloy. Tests were done under various combinations of sliding speed $(0.02 \mathrm{~m} / \mathrm{s}$ to $0.5 \mathrm{~m} / \mathrm{s})$ and normal load $(40 \mathrm{~N}$ to $1000 \mathrm{~N})$. In conjunction with common wear mechanisms, such as oxidative wear, platelet wear was also observed. It is suggested that the platelet wear observed is the consequence of a plastic ratcheting mechanism, known as 'ratcheting wear', owing to the large strains experienced at the wear interface. In addition to this, the stiffness of the wear interface was observed to drop significantly which has previously been unreported for this system. Both of these physical responses have implications for the development of a mechanistic wear model.
\end{abstract}

Keywords: Cobalt-chromium, Platelet, Ratcheting, Modelling, Sliding

\section{Introduction}

Cobalt-chromium alloys are used within industries with stringent safety requirements due to their excellent friction performance in reciprocated dry sliding applications, where other materials would fail by seizure or severe wear. In particular, they find usage in the nuclear industry as hard-facings on reactor components or in the bio-medical industry for hip implants due to their high temperature, corrosion, and wear resistance [1].

It is generally understood that cobalt-chrome alloys gain their beneficial frictional properties from the formation of an easy-shear layer [2], which is said to form more preferentially at higher loads. Additionally, these alloys undergo a martensitic phase transformation near to the surface which increase the overall hardness of the wear interface which give the alloy increased wear resistance [3]. The secondary hard-phase consisting of metallic

Preprint submitted to Wear chromium-rich carbides have been suggested to improve the abrasion resistance of such alloys [4]. Importantly, their high temperature resistance results from the presence of tungsten in the cobalt-based matrix which, in addition to increasing the melting point of the alloy, also strengthens the cobalt matrix to improve wear resistance [1]. However, the wear particles generated and ejected from the wear interface during sliding present significant health risks in the form of radioactive gamma fields [5] or poisoning [6]. Therefore, there is a great motivation to understand the wear behaviour in-situ and replace these alloys with cobalt-free alternatives.

Use of a mechanistic model of wear which captures the physical response of the system due to the loading conditions and environment, would be useful for developing an understanding of how this material behaves in-situ, and to aid the creation of cobalt-free alternatives. However, typical wear

October 11, 2018 
models used to characterise system behaviour $[7,8]$ do not capture the relevant physics with regards to changes in environment or loading conditions and there has been little push for the development of a model that can account for these conditions in the case of $\mathrm{Co}-\mathrm{Cr}$ sliding systems. Furthermore, there is still a limited understanding on how the loading conditions affect the physical response of the alloy and thus how they influence the wear mechanisms. While the general wear response of such alloys have been investigated experimentally, with a focus on laser-clad and cast alloys - identifying wear mechanisms such as carbide pull-out and fracture [9], delamination [10], and fatigue of a wear-reducing oxide layer [11] - there has not been much focus on the understanding of how these wear mechanisms occur as a result of the loading conditions for hotisostatically pressed (HIPed) cobalt-chromium.

Therefore, the aim of this paper is to gain an understanding of how wear mechanisms are influenced by loading conditions, and to identify the relevant physics at the wear interface to aid the development of a mechanistic model. A systematic study of load vs sliding distance vs speed has been conducted for a HIPed cobalt-chromium alloy under self-mated dry sliding conditions at room temperature. Relationships between the loading conditions and wear mechanisms operative at the wear interface were investigated. Wear surfaces, cross-sections of worn pins, and debris were examined under scanningelectron microscopy (SEM). These were characterised by electron-diffraction spectroscopy (EDX), xray diffraction spectroscopy (XRD), profilometry and nano-indentation. Frictional data was also collected. The experimental procedure is shown in section 2. Results are shown in section 3 and discussed in section 4 . Conclusions are given in section 5 .

\section{Experimental procedures}

\subsection{Materials and microstructure}

The material selected for this study was a cobalt-chromium based hard-facing alloy with a composition of Co-30Cr-5W-2Fe-1.1C-1.1Si. The powder particle size was in the range of $63-150 \mu \mathrm{m}$. The material was processed using a HIPing cycle of $100 \mathrm{MPa}$ at $1200 \mathrm{degC}$ for 4 hours. This resulted in a speckled microstructure as seen in Figure 1. The light grey phase corresponds to the cobaltchromium matrix. Dark spherical chromium-rich $\mathrm{M}_{7} \mathrm{C}_{3}$ carbides sit within the matrix, as shown by the dark phase, and have an average size of 1 to $3 \mu \mathrm{m}$ in diameter. The area fraction of the carbides correspond to roughly $19.5 \%$. Tiny pores of less than $1 \mu \mathrm{m}$ in diameter throughout the material are also evident, typically clustering around carbide-matrix boundaries. The typical hardness of this alloy is reported to be in the range 380-490 $\mathrm{Hv}$ [12], or 3.8-4.9 GPa.

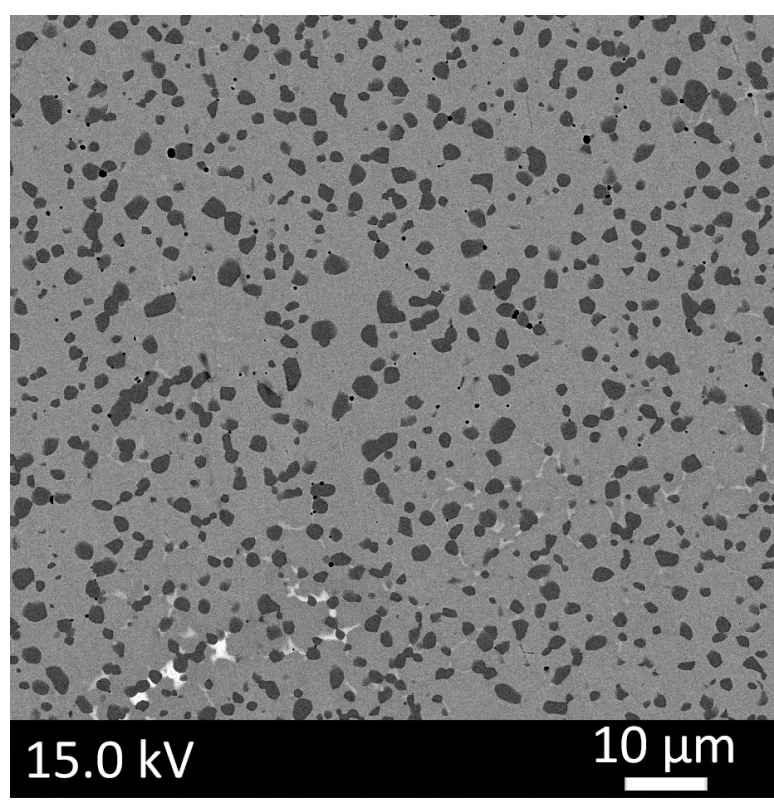

Figure 1: SEM micrograph showing the microstructure of the cobalt-chromium alloy.

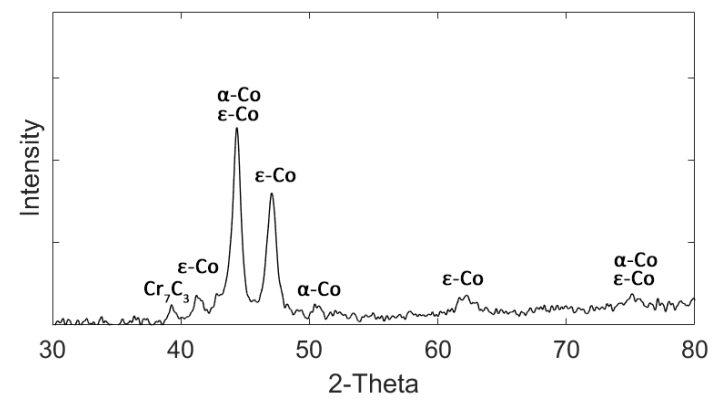

Figure 2: XRD pattern for the cobalt-chromium hard-facing alloy.

XRD analysis of the unworn specimens were also undertaken, in addition to EDX. The XRD pattern can be seen in Figure 2.

\subsection{Material properties}

Microscopic material properties were characterised using the nano-indentation method. A Berkovich diamond indenter was used in all cases 
controlled up to a depth of $500 \mathrm{~nm}$. A 20 by 20 indentation map was taken for every sample pre- and post-test with a $15 \mu \mathrm{m}$ spacing between indents.

In addition to the material properties obtained through indentation, standard uni-axial tension test was performed to gain an understanding of the bulk elastic and plastic response of the alloy as well as the total strain-to-failure. The initial material properties are shown in table 1 . The hardening response of the alloy was best captured using a Voce hardening model.

\subsection{Wear tests}

The experimental procedure used a Plint TE77 reciprocating sliding test rig under dry room conditions of $\sim 25 \mathrm{deg} C$ and relative humidity $\sim 40 \%$. A schematic for the test rig is shown in Figure 3. Frictional data was recorded via a transducer connected to the TE77 rig.

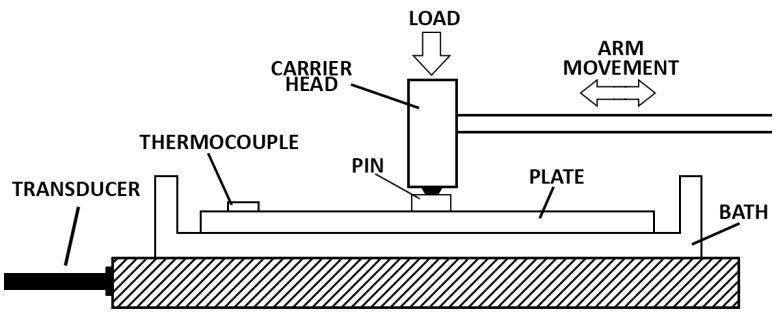

Figure 3: Schematic of the experimental rig.

The wear tests performed were separated into two categories: a set for observing the influence of sliding speed and load on the wear mechanisms, and a set for the influence of very high loads at slower speeds. Tests to see the influence of sliding distance on the evolution of wear were also performed. The full test matrix can be seen in table 2 .

The sliding geometry chosen was an area-on-flat with a cylindrical pin of $10 \mathrm{~mm}$ and $8 \mathrm{~mm}$ diameter for the variable velocity and load cases respectively to allow for higher nominal pressures in the latter experiments. These were slid against plates of dimension $20 \times 60 \times 3 \mathrm{~mm}^{3}$. The chosen mating for each experiment was like-on-like. Each test surface was diamond lapped to a finish of $0.2 \mu \mathrm{m} \pm 0.05$ Ra. The reason for selecting these parameters for the wear tests were to reflect an application within industry.

Post-wear characterisation consisted of weight change measurements for the pin and profilometer data for the plate and pin. Post-wear surface texture data were also calculated from the profilometer data. Wear scars were characterised using EDX, SEM, and XRD analysis. Pins were also crosssectioned and hardness measurements were taken with respect to depth from the wear surface using nano-indentation and a Vickers hardness tester. Debris at the edge of the wear track was also collected for analysis.

\section{Results}

\subsection{Wear tests}

The frictional data collected for all experiments showed a decrease in the dynamic coefficient of friction with load. The observed range was 0.5 to 0.25 .

\subsubsection{Variable speed tests}

Figures 4 through 6 show the post-wear SEM micrographs from $0.05 \mathrm{~m} / \mathrm{s}$ to $0.50 \mathrm{~m} / \mathrm{s}$ for the pin wear surface, cross-section of the pin surface, and wear debris. EDX of these micrographs are also shown.

The surface SEM micrographs are shown in Figure 4. Primarily adhesive wear is seen throughout all experiments. Likewise material appears to have been pressed and displaced across the surface as evident in Figure 4(b) and (c). Interestingly, what appears to be a platelet is peeling from the surface as seen in Figure $4(\mathrm{~b})$ for the $0.1 \mathrm{~m} / \mathrm{s}$ test. Importantly, this platelet is of the same order as the wear particle diameters seen for the corresponding experiment in Figure 6. A large plate-like piece of material appears to have adhered and been pushed along in the high $0.50 \mathrm{~m} / \mathrm{s}$ test in Figure 4(c). EDX of the surface confirms that these wear surfaces consist primarily of $\mathrm{Co}, \mathrm{Cr}$, and $\mathrm{W}$ as expected. There is also a high degree of oxygen which is expected due to the passivating nature of chromium [13]. A combination of several wear mechanisms is typical for this alloy. As demonstrated by the EDX results, a combination of oxidative mechanisms along with adhesive and fatigue mechanisms can be seen.

The cross-sections of the worn pin shown in Figure 5 show clear evidence of subsurface cracks forming parallel to the wear surface. The damaged surface appears to lift off and away from the pin forming a thin-lip before breaking off to become entrained in the contact interface as a wear particle. Interestingly, for the $0.1 \mathrm{~m} / \mathrm{s}$ test in Figure $5(\mathrm{~b})$ shows what appears to be a wear particle consisting of highly-strained oxidated material similar to what can be seen in mechanically-mixed-layers [2]. 
Table 1: Material properties for the cobalt-chromium alloy.

\begin{tabular}{|c|c|c|c|c|}
\hline $\begin{array}{l}\text { Young's Modulus } \\
\text { (Tension test) } \\
\text { (GPa) }\end{array}$ & $\begin{array}{l}\text { Young's Modulus } \\
\text { (Nano-indentation) } \\
(\mathrm{GPa})\end{array}$ & $\begin{array}{l}\text { Strain-to-failure } \\
(\%)\end{array}$ & $\begin{array}{l}\text { Vickers Hardness } \\
(\mathrm{Hv})\end{array}$ & $\begin{array}{l}\text { Nano-hardness } \\
(\mathrm{GPa})\end{array}$ \\
\hline 215 & 220 & 2.5 & 450 & 5.0 \\
\hline
\end{tabular}

Table 2: Range of experimental parameters used for different combinations for the wear tests.

\begin{tabular}{llll}
\hline $\begin{array}{c}\text { Load } \\
(\mathbf{N})\end{array}$ & $\begin{array}{c}\text { Pressure } \\
(\mathbf{M P a})\end{array}$ & $\begin{array}{c}\text { Velocity } \\
(\mathbf{m} / \mathbf{s})\end{array}$ & $\begin{array}{c}\text { Distance } \\
(\mathbf{m} / \mathbf{s})\end{array}$ \\
\hline 40 & 0.5 & 0.05 & 500 \\
160 & 2.0 & 0.10 & \\
240 & 3.0 & 0.50 & \\
320 & 4.0 & & \\
400 & 5.0 & & \\
\hline 600 & 12.0 & 0.02 & 100 \\
700 & 14.0 & & \\
800 & 16.0 & & \\
900 & 18.0 & & \\
1000 & 20.0 & & \\
\hline
\end{tabular}

a)
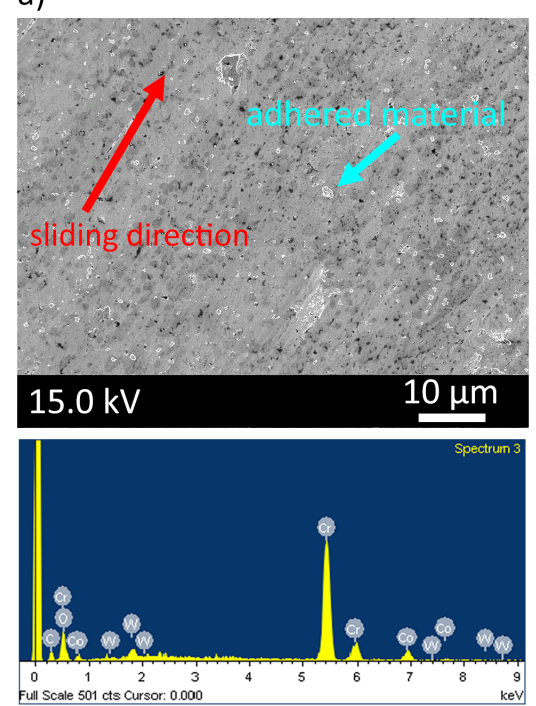

b)
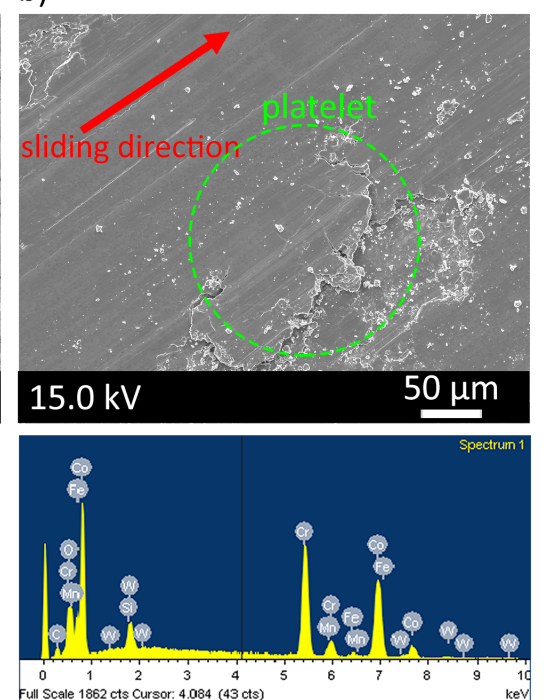

c)

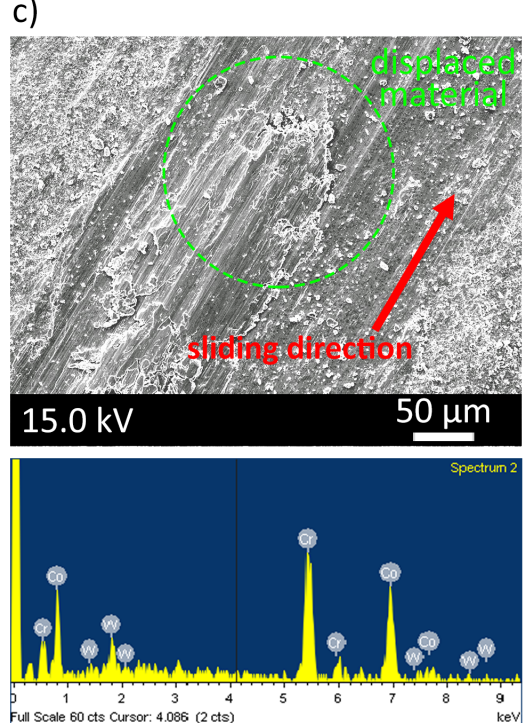

Figure 4: SEM micrograph of the wear surface on the pin for the variable speed tests with a corresponding EDX measurement below. a) $0.05 \mathrm{~m} / \mathrm{s} \mathrm{b}) 0.10 \mathrm{~m} / \mathrm{s} \mathrm{c}$ ) $0.5 \mathrm{~m} / \mathrm{s}$ 
Figure 5(a) shows what appears to be detachment of material however there appears to be oxidated $\mathrm{Co}-\mathrm{Cr}$ in between the separating material and the pin. All the cracks appear to occur no further than $10 \mu \mathrm{m}$ below the surface. Every wear surface had evidence of small scratches, of the same order as the carbide radius, which suggests that carbide pull-out is occuring. Such a mechanism was observed by $\mathrm{Yu}$ et al. [9].

The typical debris observed throughout all of the $400 \mathrm{~N}$ variable speed tests appears to be platelike. The size of the debris consists of smaller broken up portions of debris no larger than $10 \mu \mathrm{m}$ in diameter with the largest debris being above $50 \mu \mathrm{m}$. The wear debris show evidence of cracking and fracture throughout their surface which suggest they are brittle. Smaller chip-like wear particles are also seen. EDX shows that the debris is high in oxygen and chromium. The thickness of debris seen in the $0.05 \mathrm{~m} / \mathrm{s}$ to $0.5 \mathrm{~m} / \mathrm{s}$ tests all appear to be less than $10 \mu \mathrm{m}$ in thickness. The $0.5 \mathrm{~m} / \mathrm{s}$ wear debris appears to a type of severe metallic wear given the high degree of directionality on the debris surface [14].

\subsubsection{Variable load tests}

Figures 7 through 9 show the post-wear SEM micrographs for the $0.02 \mathrm{~m} / \mathrm{s}$ tests for the pin wear surface, cross-section of the pin surface, and wear debris. EDX of these micrographs are also shown.

Debris is shown to be highly strained and displaced across the wear surface in Figure 10. There is clear evidence of ridges induced by displacement of material in Figure 7(a). The underlying structure of carbides cannot be seen at high magnifications, further suggesting that material has been highly strained and smeared across the surface as to cover or destroy the carbide structure completely.

As in the variable speed tests, Figure 8 shows subsurface damage and cracking occurring in the pin. Once again, highly-strained mechanically mixed material appears to be entrained in the fracture surface. Interestingly, all the fracture surfaces in the pin appear to occur approximately 3 $\mu \mathrm{m}$ below the wear interface with cracks nucleating and propagating around the carbide boundaries. In some cases, the fracturing material appears to be a combination of mechanically-mixed material and the bulk material of the pin.

Figure 9 shows debris from the high load tests. Similar to the lower load tests, the wear debris appears to be plate-like. The material is again brittle and thin as shown by the cracks in the debris.

In all tests, evidence of material being strained and displaced across the wear surface is seen. Figure 10 shows how the material is displaced to the edge of the pin. This type of deformation is characteristic of all the tests seen at and above $400 \mathrm{~N}$. The higher speed tests show a more pronounced deformation at the pin edge. This material is typically thin and appears to be in the process of fracturing off, as seen in the high speed 0.5 test. A similar type of deformation, considered as 'shear tongues', was reported for laser-clad stellites by Persson [2].

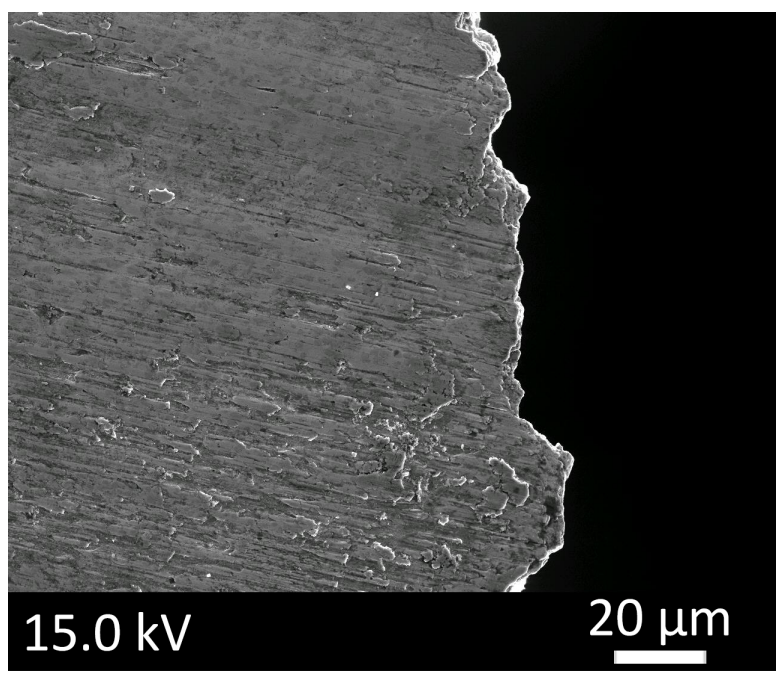

Figure 10: SEM micrograph of material being displaced towards the pin edge for the $600 \mathrm{~N}$ test.

To avoid making a linear assumption in the wear loss, the wear results have been reported in terms of volume loss. Figure 11 shows the volume losses from all tests. With the exception of Figure 11(c) corresponding to the $0.1 \mathrm{~m} / \mathrm{s}$ pin wear, none of the results show a linear trend and therefore are nonArchard in their wear behaviour. At high loads, above $400 \mathrm{~N}$, the volume loss seems relatively insensitive to load. Perhaps somewhat paradoxically, the higher load shows a lower volume loss with material removal being more sensitive to sliding speed. Reasons for this are explored in the next section.

The volume loss for the pin in the high speed tests, shown in Figure 11(d) show a parabolic trend rather than a linear trend. The corresponding wear of the plate instead shows a logarithmic trend with the wear volume plateauing to a value of approximately $0.5 \times 10^{-9} \mathrm{~m}^{3}$.

Evolution of the surface texture parameters is shown in Figure 12. 
a)
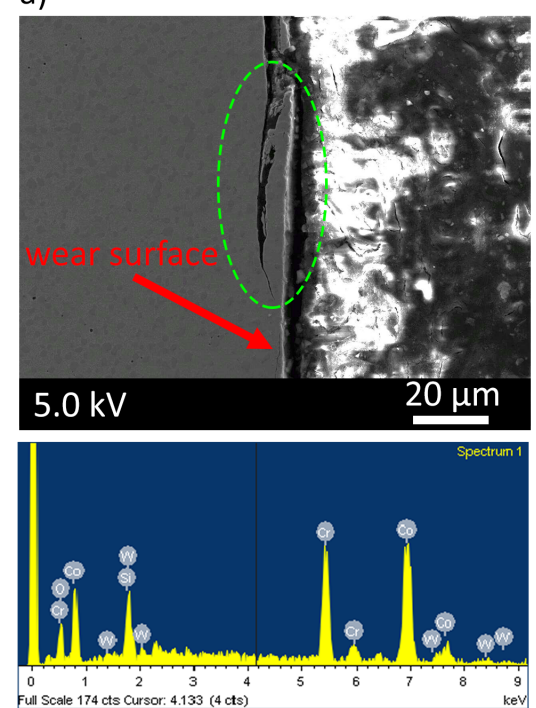

9 b)
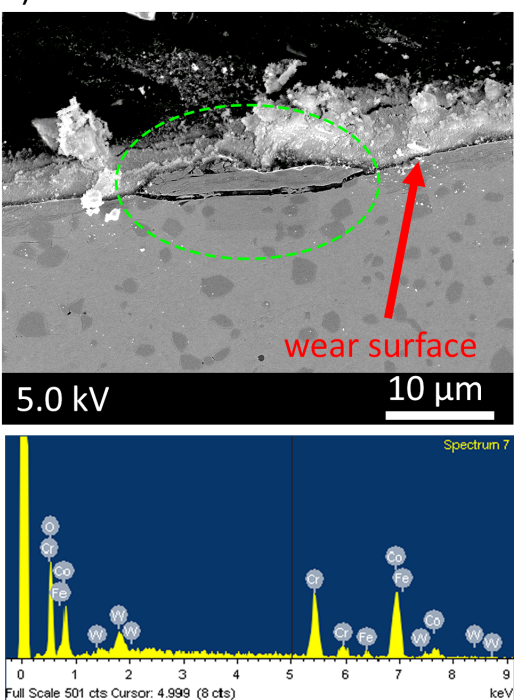

c)

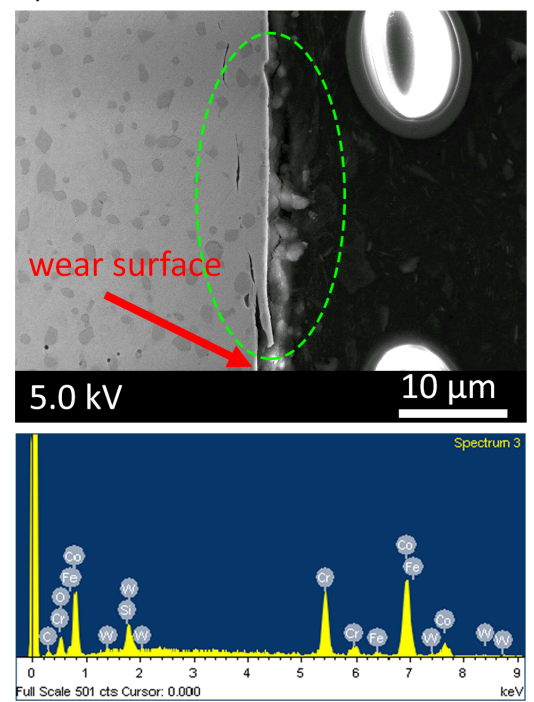

Figure 5: SEM micrograph of the pin cross-section for the variable speed tests with a corresponding EDX measurement below. a) $0.05 \mathrm{~m} / \mathrm{s} \mathrm{b}) 0.10 \mathrm{~m} / \mathrm{s} \mathrm{c}) 0.5 \mathrm{~m} / \mathrm{s}$

a)
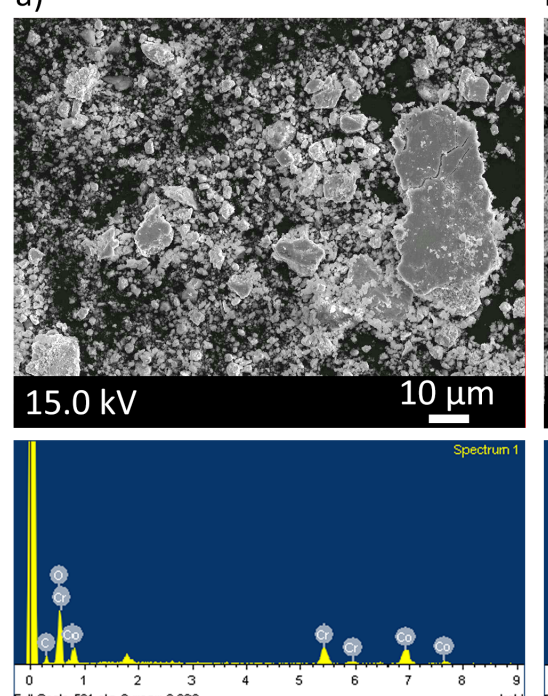

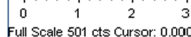

b)
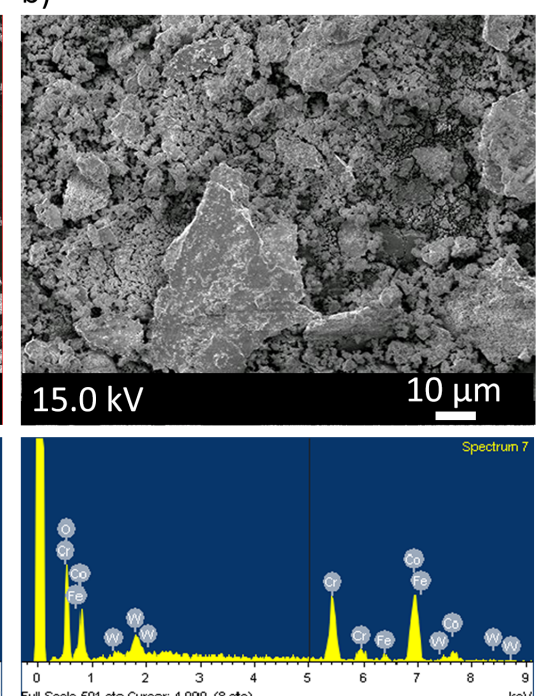

c)
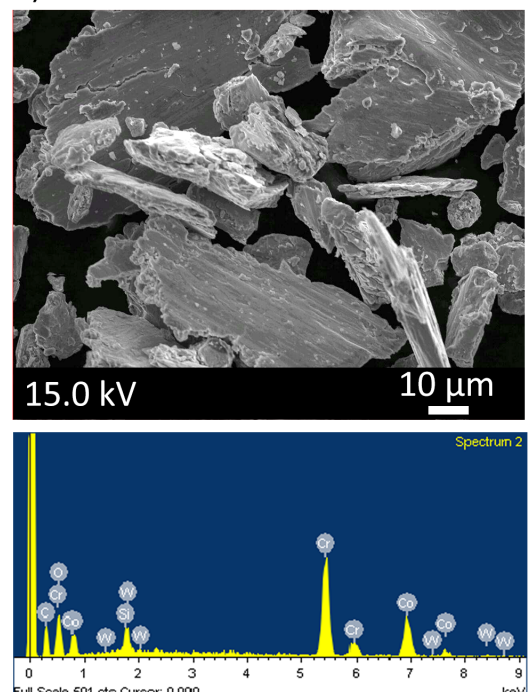

Figure 6: SEM micrograph of the wear debris from the variable speed tests with a corresponding EDX measurement below. a) $0.05 \mathrm{~m} / \mathrm{s} \mathrm{b}) 0.10 \mathrm{~m} / \mathrm{s} \mathrm{c}) 0.5 \mathrm{~m} / \mathrm{s}$ 
b)
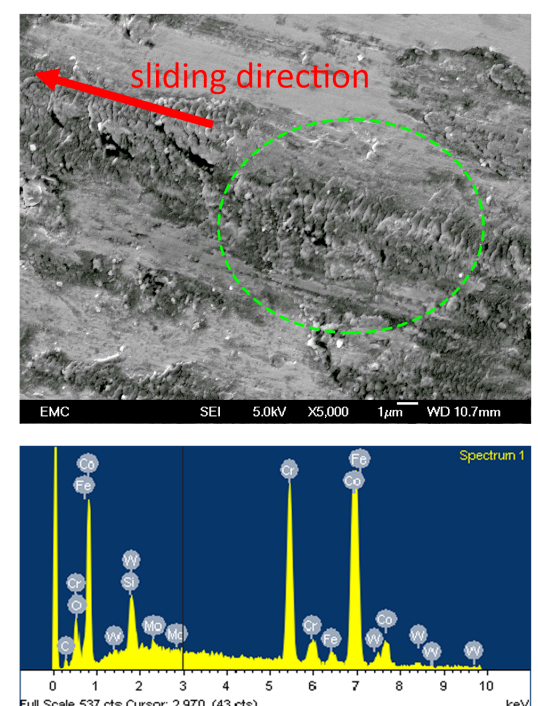

ull Scale 537 cts Cursor. 2.970 ( 43 cts)
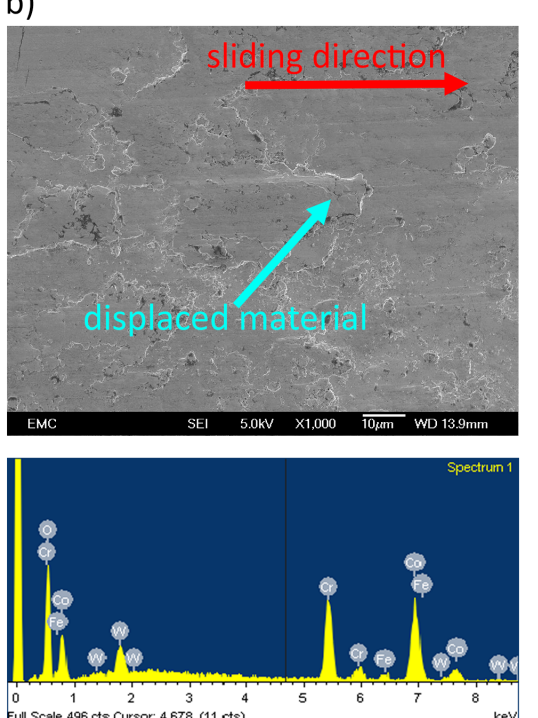

c)
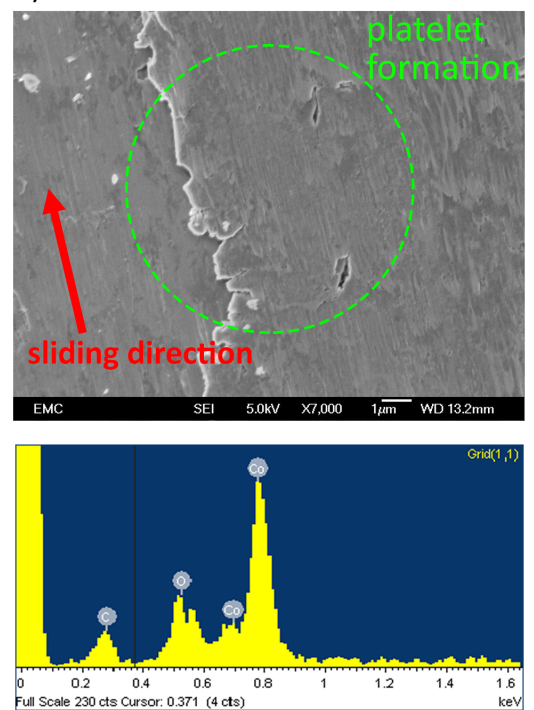

Figure 7: SEM micrograph of the wear surface on the pin for the variable load tests with a corresponding EDX measurement below. a) $600 \mathrm{~N} \mathrm{b)} 800 \mathrm{~N} \mathrm{c)} 1000 \mathrm{~N}$

a)
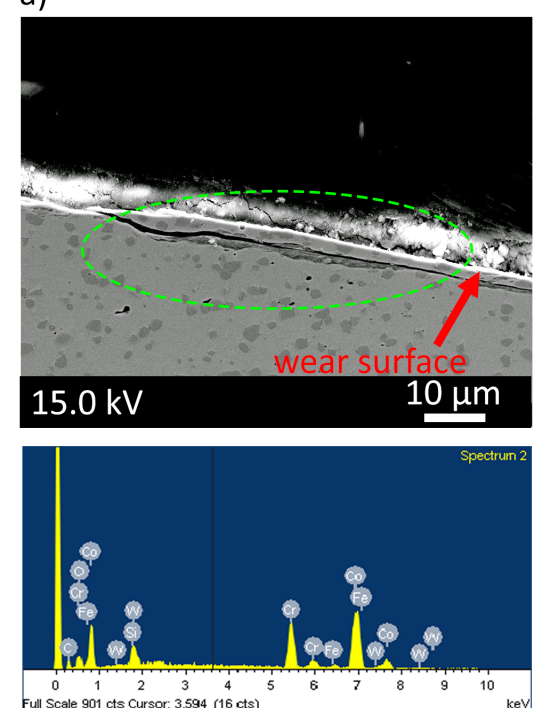

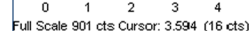

b)
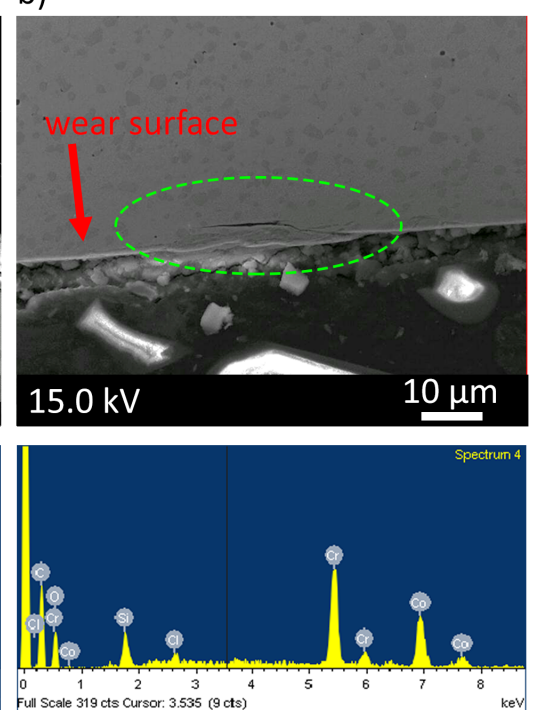

c)
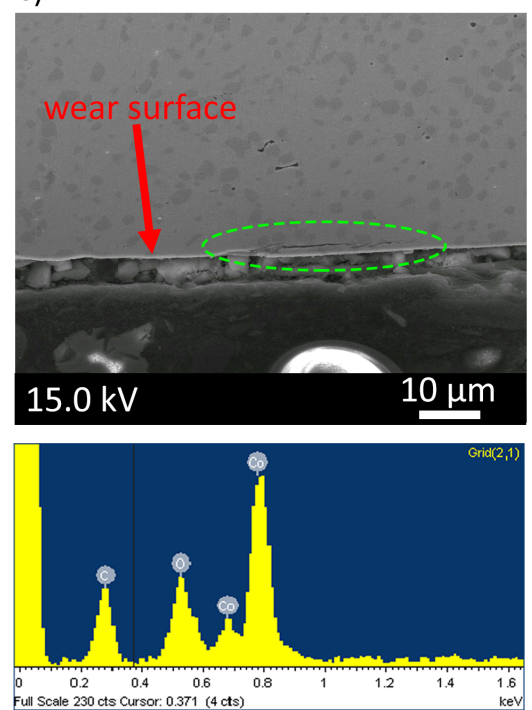

Figure 8: SEM micrograph of the pin cross-section for the variable load tests with a corresponding EDX measurement below. a) $600 \mathrm{~N} \mathrm{b)} 800 \mathrm{~N} \mathrm{c)} 1000 \mathrm{~N}$ 
a)
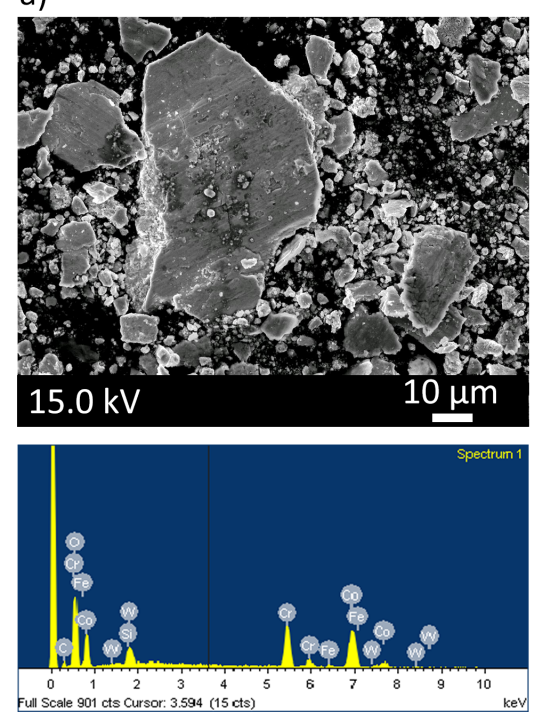

b)
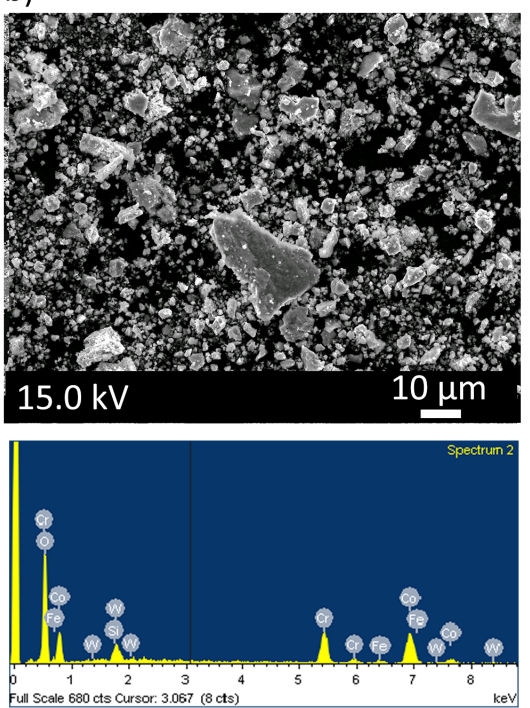

c)
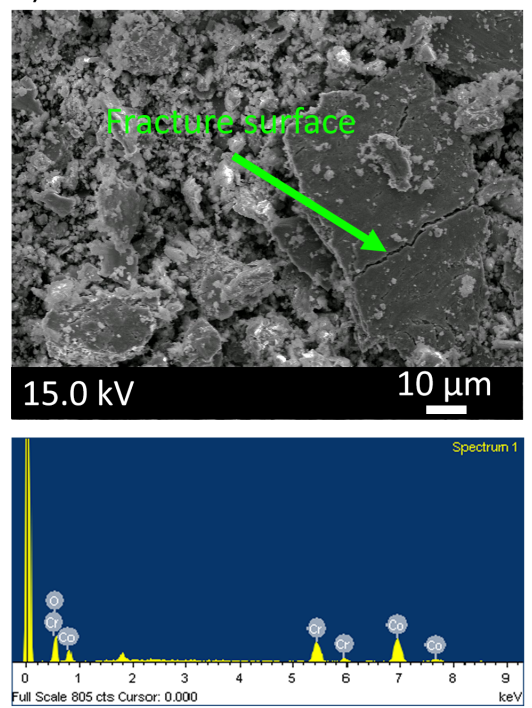

Figure 9: SEM micrograph of the wear debris from the variable load tests with a corresponding EDX measurement below. a) $600 \mathrm{~N} \mathrm{b)} 800 \mathrm{~N} \mathrm{c)} 1000 \mathrm{~N}$

\subsection{Nano-hardness measurements}

Importantly, evolution of the material properties at the wear surface and into the bulk of worn pin are shown in Figure 13. It is shown that for all the high load tests, the hardness of the pin increases which is expected. Intriguingly, the Young's modulus of the pin shows a marked decrease towards the wear surface. This has the effect of increasing the over-all elastic strain-to-failure ratio $\mathrm{H} / \mathrm{E}$ [15]. Reasons behind the reduction in stiffness while giving a resulting increase in hardness are discussed in the next section.

It is interesting to note that the depth of formation appears to reach as deep at $100 \mu \mathrm{m}$ on average for all the wear tests. This scale of changes to the material properties appears to be reflected in the geometrical deformation of the pin itself, as shown in Figure 14 for the $600 \mathrm{~N}$ pin at $0.02 \mathrm{~m} / \mathrm{s}$. This type of lipping on the edge of the pin was characteristic for all of the wear tests thus far. No such lipping was observed on the unworn pin.

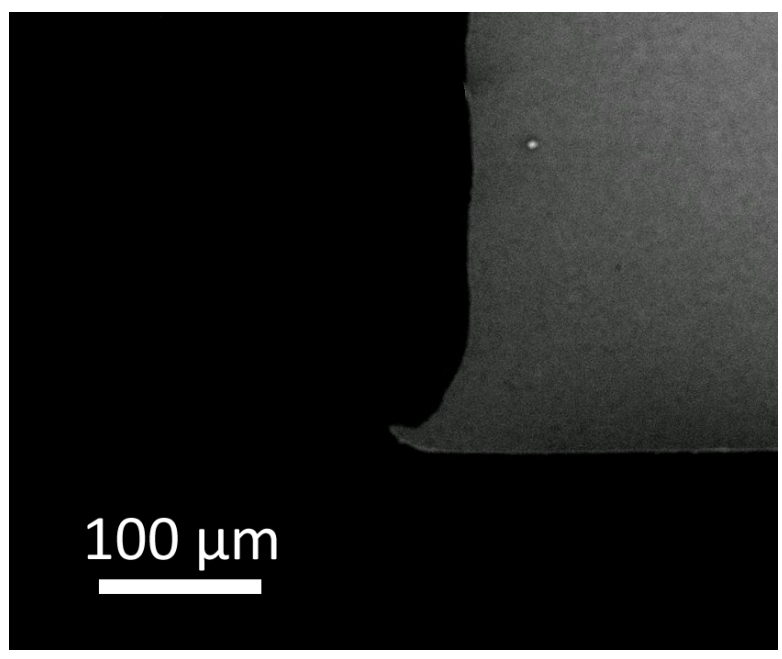

Figure 14: Optical microscope image showing the scale of deformation towards the pin edge for the $600 \mathrm{~N}$ test.

\section{Discussion}

\subsection{Wear tests}

This first section discusses the common trends and phenomena seen throughout each wear tests.

The wear tests for $400 \mathrm{~N}$ and above all show very similar wear mechanisms, with varying degrees of severity. Majority of the debris has a plate-like morphology to it, with smaller chip-like or adhesive debris. In addition to this, most of the wear 
a)

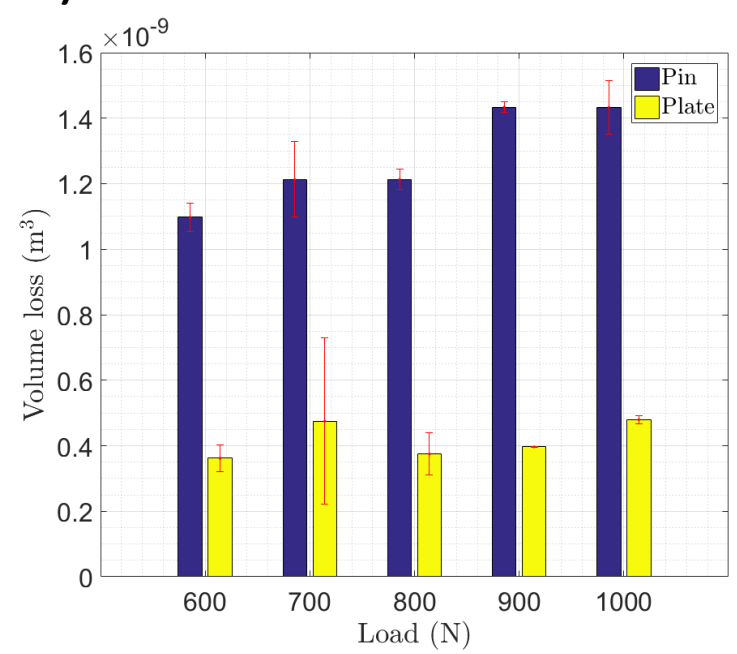

c)

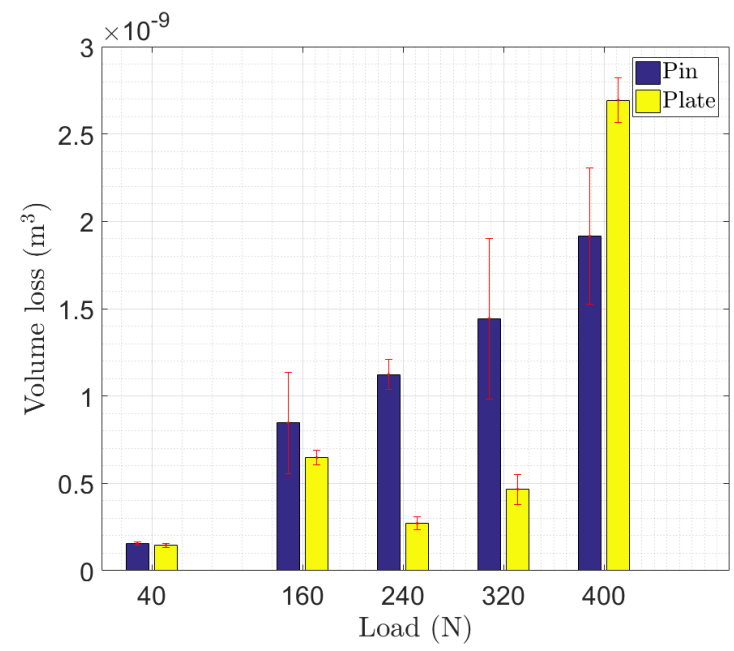

b)

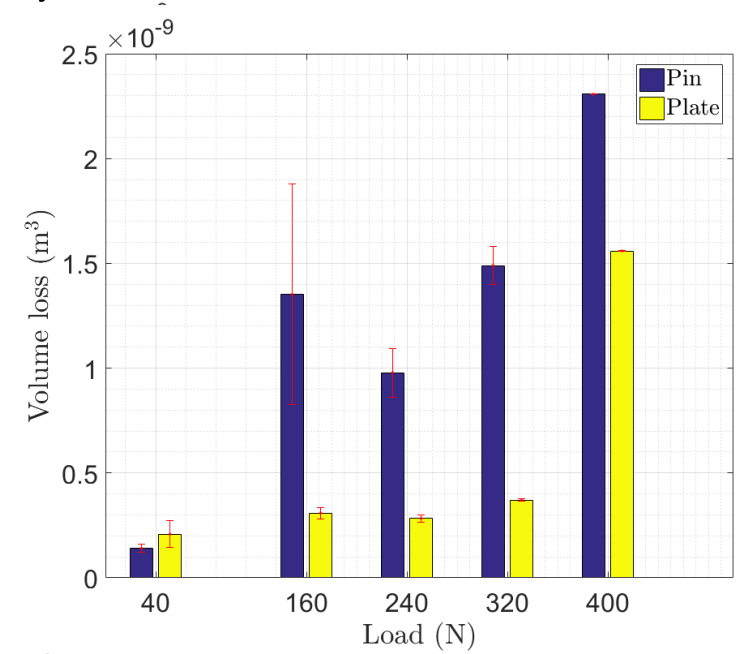

d)

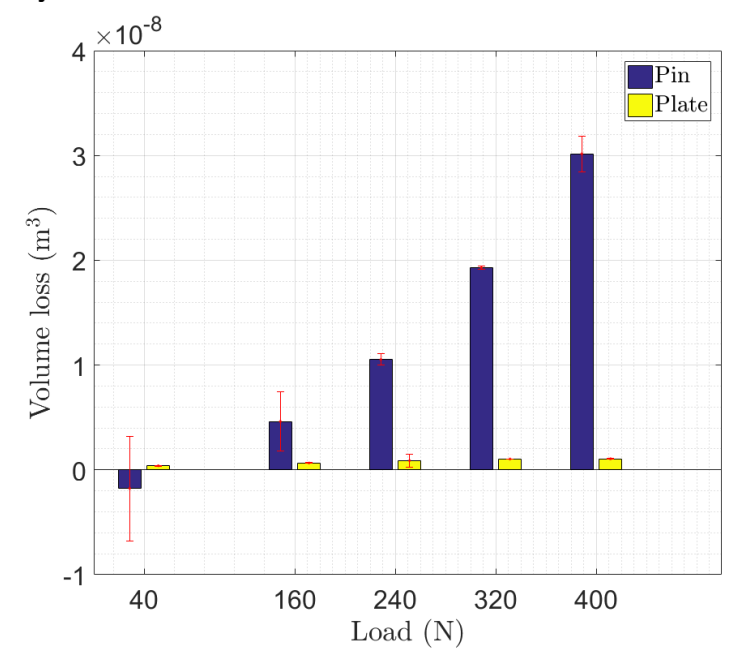

Figure 11: Wear volume vs load plots for a) $0.02 \mathrm{~m} / \mathrm{s} \mathrm{b}) 0.05 \mathrm{~m} / \mathrm{s} \mathrm{c}$ ) $0.10 \mathrm{~m} / \mathrm{s} \mathrm{d}) 0.50 \mathrm{~m} / \mathrm{s}$ 
a)

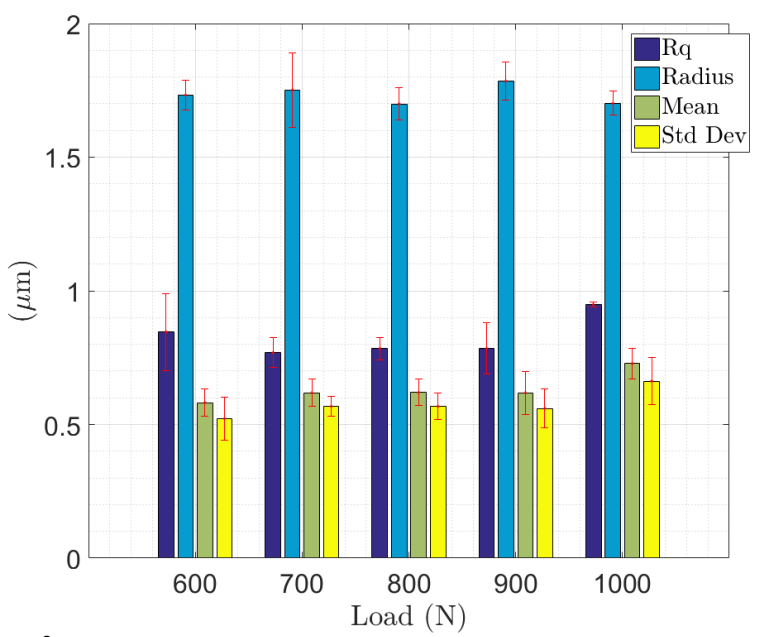

c)

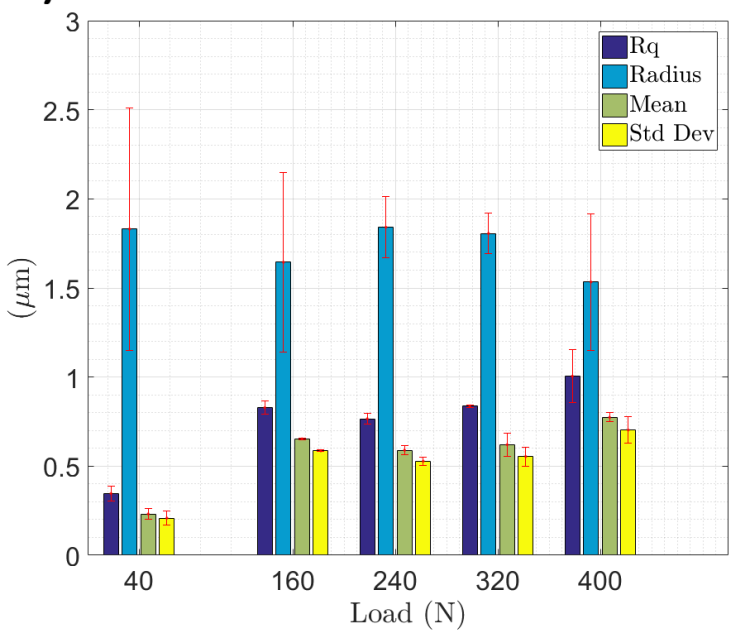

b)

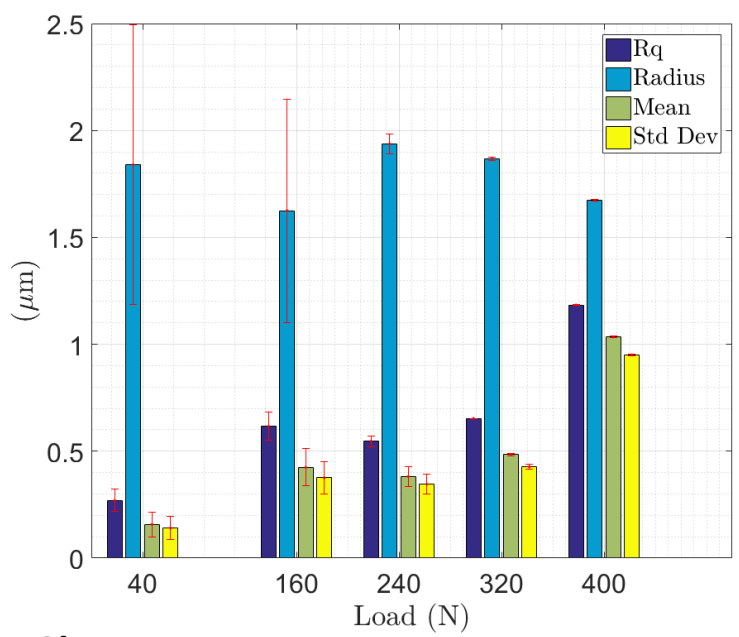

d)

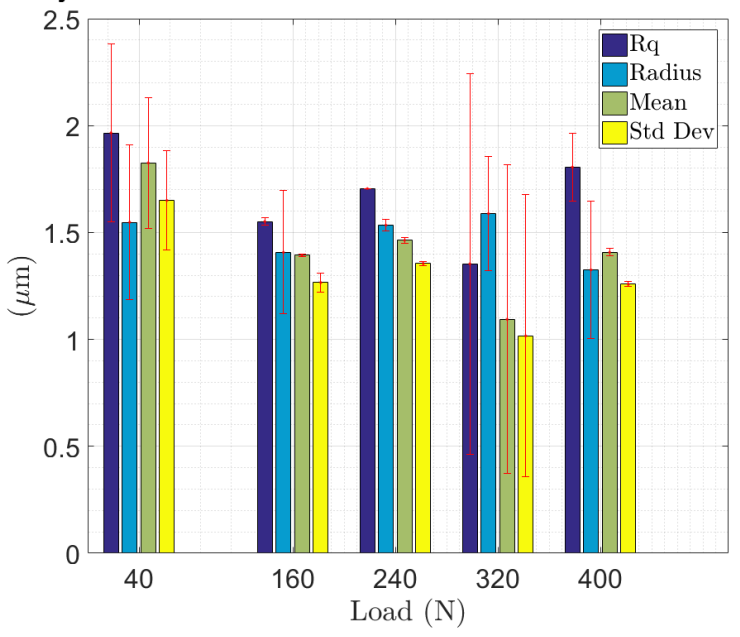

Figure 12: Surface texture parameters vs load plots for a) $0.02 \mathrm{~m} / \mathrm{s} \mathrm{b}) 0.05 \mathrm{~m} / \mathrm{s} \mathrm{c}) 0.10 \mathrm{~m} / \mathrm{s} \mathrm{d}) 0.50 \mathrm{~m} / \mathrm{s}$

a)

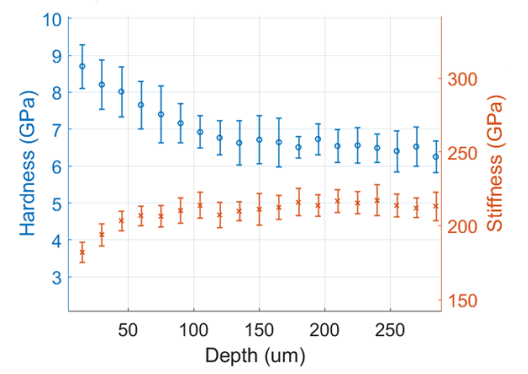

b)

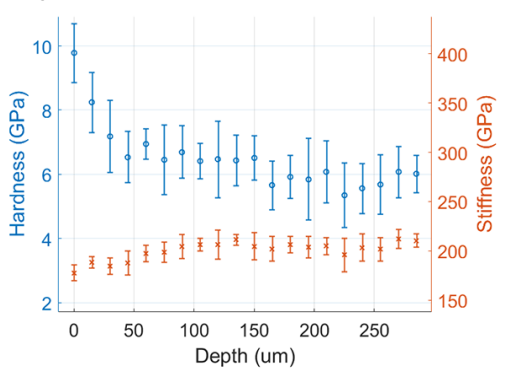

c)

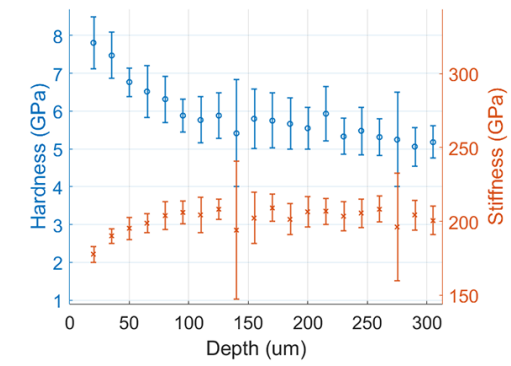

Figure 13: A plot of the nano-indentation results for hardness vs depth and elastic modulus vs depth. a) $600 \mathrm{~N}$ b) $800 \mathrm{~N}$ c) $1000 \mathrm{~N}$ 
surfaces appear to consist of strained material being displaced across the surface, or in some cases demonstrate the peeling-off or adhesion of plate-like wear particles. Formation of these particles appear to be the consequence of subsurface crack formation, typically less than $10 \mu \mathrm{m}$ below the surface as well as the fracturing of displaced material from the pin edge - leading to the formation of platelets. This type of detachment was most noticeable in the hide speed tests. It is often tacitly assumed that the wear process is Archard-like, in which wear debris is considered hemispherical, but the present results contradict this assumption. Rather, given the type of physical phenomena observed (platelets, subsurface fractures, displacement of material, and gross deformation at the pin edge), the wear process is more likely to be wear generated as a result of plastic ratcheting [16].

Plastic ratcheting is said to occur when, under cyclic loading, the load is high enough such that there is a unidirectional accumulation of plastic shear strain with each passing contact of the asperities and would explain the scale of the deformation seen at the pin edge on Figure 14. This is a consequence of the high stresses experienced under the point of contact, as any residual stresses or work-hardening introduced during running in are not enough to prevent further plastic deformation [17]. These plastic strains cause ductile cracks to propagate parallel to the subsurface, which grow with every cycle and eventually turn up towards the surface to form a wear particle, and can be seen clearly in Figures 8 and 5. This detached material is then free to be displaced across the wear surface as shown in Figures 7 and 4 . These cracks must be plastic in nature as, if the fracture were an elastic process, the stress field generated under frictional sliding would suppress the necessary elastic fracture modes to generate the cracks seen on the crosssections [18]. In addition to subsurface fracture, thin material displaced to the edge of the contact zone may fracture off to form a platelet wear particle as seen in Figure 10. This type of wear has also been seen for laser-clad stellites under high loads $[2,10]$.

With regards to the depth at which cracks nucleate being approximately $10 \mu \mathrm{m}$ : a Hertzian analysis of a sphere penetrating a flat surface is performed to see if this coincides with the maximum shear stress experienced under an asperity contact. Using the well-established equation for maximum shear stress as a function of contact radius [19]:

$$
z_{\max }=0.48 a
$$

where $z_{\max }$ refers to the depth below the surface where the maximum shear stress, $\tau_{\max }$, is experienced and $a$ is the contact radius. Substituting in $z \approx 3 \mu \mathrm{m}$ and rearranging the equation, it can be seen that the corresponding contact radius would be $20 \mu \mathrm{m}$. This number is significantly larger than the average post-wear asperity radius shown in Figure 12. As such, it is highly unlikely for a contact radius of this magnitude to be reached elastically with this corresponding asperity radius.

It is interesting to note that in the monotonic test the strain-to-failure was $2 \%$ in table 1 which is common for this family of CoCr alloys [12], yet the pin is experiencing gross deformation at the edge of the pin much greater than this failure strain. Gross deformation at the wear surface and into the bulk was also seen by Persson [2] under $1500 \mathrm{~N}$, Frenk and Kurz [10] under 50 N, and Cabrol [20] under $5000 \mathrm{~N}$ of $200 \%, 50 \%$, and $1600 \%$ respectively for laser-clad stellites. Such deformation is reminiscent of pearlitic rail steels which are known to undergo ratchetting and fatigue wear [21]. The reason behind this seemingly ductile response of a brittle metal can be explained by the presence of high hydrostatic pressures. It has been shown that brittle metals behave as ductile metals when subjected to hydrostatic pressure [22, 23], and it is typical under rough surface contact for high stresses generated under the point of contact to cause high hydrostatic pressures in the subsurface [18]. Therefore, one cannot assume the material will necessarily behave in a brittle manner during wear in the presence of these pressures. A consequence of this is that, if one chooses to simulate wear using a damage criterion based on the strain-to-failure, results from a monotonic test will over-predict the wear volume.

The volume loss results shown in Figure 11 show that, at low speeds of 0.02 to $0.10 \mathrm{~m} / \mathrm{s}$, the volume loss is typically below $4 \times 10^{-9} \mathrm{~m}^{3}$, while at $0.50 \mathrm{~m} / \mathrm{s}$ the volume of wear an order of magnitude higher. Furthermore, the variable load tests demonstrate some of the lower volume loss. This discrepancy may first be explained through frictional heating of the material at higher speeds lending to increased ductility and perhaps further wear. This would explain the volume of adhesive wear in Figure 4(c). However, it should be noted that at higher speeds more material was ejected further away from the 
wear track while for slower speeds more material remained at the edge of the wear track. A consequence of this is that there is a greater chance for material to be reintroduced into the contact area resulting in an overall lower volume loss.

\subsection{Nano-hardness measurements}

The nano-hardness measurements shown in Figure 13 show a reduction in stiffness along with an increase in hardness. Such a phenomena has not been reported before. The trends in the hardness and stiffness data may relate to the grain size evolution of the microstructure after wear. As per the Hall-Petch effect, the hardness of materials tends to increase with grain refinement as a consequence of reduced dislocation pile-up at grain boundaries. An inverse relationship between grain size and stiffness has also been demonstrated experimentally and in numerical simulations [24, 25, 26]. This is said to be due to the increased presence of pores and cracks through the nano-grain structure. Grain-refinement and the presence of nanograins are typical after tribological tests for $\mathrm{CoCr}$ alloys [27], and typically leads to a type of fatigue wear known as "nano-grain wear" [28], consisting of pulled-out grains which form small globular particles on the wear surface - these typically cluster around grooves and oxide boundaries. This type of wear can be observed in Figure 15 and has been seen throughout all wear tests in varying degrees.

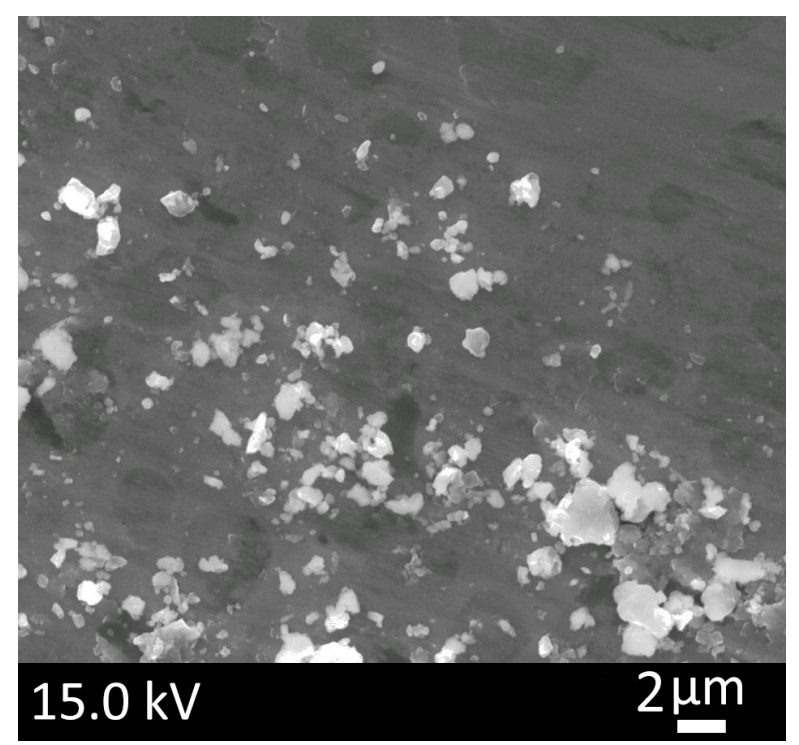

Figure 15: SEM image demonstrating the type of small ad-
The increase in hardness with a reduction in stiffness at the wear surface causes the $\mathrm{H} / \mathrm{E}$ value to increase. A consequence of this is that the surface material is more wear resistant as a result of being able to undergo greater elastic strain before material failure [15]. The fracture toughness of a material is proportional to this parameter and is said to lead to an over-all lower volume loss. Importantly, the changes in the material properties during sliding must be accounted for in a model of wear; variations in material properties naturally affects the stress field under the point of contact which will affect the ratchetting response of the alloy.

\section{Conclusions}

A plastic ratcheting wear mechanism is operative in the $\mathrm{CoCr}-\mathrm{CoCr}$ system, in conjunction with other wear mechanisms, according to the theory of ratcheting wear [16]. The evidence that supports this is:

- Plastic deformation mechanism causing the initiation and propagation of ductile cracks in the subsurface; typically at carbide boundaries or pores.

- Material is displaced towards the pin edge whereupon detachment of the material due to elastic fracture forms a wear-particle.

- Debris is thin and plate-like with debris size being as large as $100 \mu \mathrm{m}$ diameter in some cases.

- Debris thickness was no deeper than $10 \mu \mathrm{m}$; of the same order as the cracking shown in the cross-sections.

- Edge of the pin is severely deformed after each test as the result of cumulative plastic strain.

- Non-Archard trends in wear volume data.

- Evidence of micro-structural deformation typical in rail steels (known to undergo ratcheting wear) has been seen in the literature $[2,10]$

For all experiments, the observed coefficients of friction were in the range of $0.50-0.25$ which is similar to those observed in the literature. Likewise, the volume loss experienced under the given loading conditions was in the same range as those from 
literature, typically corresponding to specific wearrates of the order $0.5 \times 10^{-5}-10.0 \times 10^{-5} \mathrm{~mm}^{3} / \mathrm{Nm}$ and $0.5 \times 10^{-5}-1.0 \times 10^{-5} \mathrm{~mm}^{3} / \mathrm{Nm}$ for the pin and plate respectively $[9,29,30,2,31]$. For every test, wear debris is ejected and accumulates at the edge of the wear track for subsequent sliding cycles under low speed - for higher speeds the debris was ejected further from the wear track and would not be reintroduced.

Further to this, the evolution of material properties towards the wear surface saw a reduction in Young's modulus with an increase in hardness. This was likely to be due to grain refinement in the subsurface, and is supported by computational experiments and implied by the evidence of nano-scale wear particles across the wear surface [28]. Grain refinement would also explain the increase in hardness despite a reduction in the modulus.

\section{References}

[1] P. Crook, Cobalt-base alloys resist wear, corrosion, and heat, Advanced Materials \& Processes 145 (4) (1994) $27-30$.

[2] D. H. E. Persson, On the mechanisms behind the tribological performance of stellites, Thesis, uppsala University (2005).

[3] S. Atamert, J. Stekly, Microstructure, wear resistance, and stability of cobalt based and alternative iron based hardfacing alloys, Surface Engineering 9 (3) (1993) 231240.

[4] V. M. Desai, C. M. Rao, T. H. Kosel, N. F. Fiore, Effect of carbide size on the abrasion of cobalt-base powdermetallurgy alloys, Wear 94 (1) (1984) 89-101.

[5] K. F. Dufrane, H. Ocken, Measurements of wear in nuclear-components, Wear 101 (1) (1985) 13-31.

[6] B. Green, E. Griffiths, S. Almond, Neuropsychiatric symptoms following metal-on-metal implant failure with cobalt and chromium toxicity, BMC Psychiatryl 17 (33) (2017) 5 .

[7] J. F. Archard, Contact and rubbing of flat surfaces, Journal of Applied Physics 24 (8) (1953) 981.

[8] V. Hegadekatte, N. Huber, O. Kraft, Finite element based simulation of dry sliding wear, Modelling and Simulation in Materials Science and Engineering 13 (1) (2005) 57-75.

[9] H. Yu, R. Ahmed, H. D. Lovelock, S. Davies, Influence of manufacturing process and alloying element content on the tribomechanical properties of cobalt-based alloys, Journal of Tribology-Transactions of the Asme $131(1)$.

[10] A. Frenk, W. Kurz, Microstructural effects on the sliding wear-resistance of a cobalt-based alloy, Wear $174(1-$ 2) (1994) 81-91.

[11] H. So, The mechanism of oxidational wear, Wear 184 (2) (1995) 161-167.

[12] Stellite 6 alloy: Technical data. URL http://stellite.co.uk/Portals/0/Stellite\%206\%20Final.palfer-clad stellite alloy 6, Wear 192 (1-2) (1996) 78-84.
[13] U. Malayoglu, A. Neville, H. Lovelock, Assessing the kinetics and mechanisms of corrosion of cast and hiped stellite 6 in aqueous saline environments, Corrosion Science 47 (8) (2005) 1911-1931.

[14] B. J Roylance, J. Williams, R. Dwyer-Joyce, Wear debris and associated wear phenomena: Fundamental research and practice 214 (2000) 79-105.

[15] A. Leyland, A. Matthews, On the significance of the $\mathrm{h} / \mathrm{e}$ ratio in wear control: a nanocomposite coating approach to optimised tribological behaviour, Wear $246(1-2)$ (2000) 1-11.

[16] A. Kapoor, Wear by plastic ratchetting, Wear 212 (1) (1997) $119-130$.

[17] J. A. Konig, Shakedown of Elastic-Plastic Structures, Elsevier, 1987.

[18] K. L. Johnson, Contact mechanics and the wear of metals, Wear 190 (1995) 162-170.

[19] K. L. Johnson, Contact Mechanics, Cambridge University Press, 1985, cambridge Books Online. URL http://dx.doi.org/10.1017/CB09781139171731

[20] E. Cabrol, C. Boher, V. Vidal, F. Rezai-Aria, F. Touratier, Plastic strain of cobalt-based hardfacings under friction loading, Wear 330 (2015) 354-363.

[21] Deterioration of rolling contact fatigue life of pearlitic rail steel due to dry-wet rolling-sliding line contact, Wear 197 (1) (1996) $255-265$.

[22] F. P. Bullen, F. Henderson, H. L. Wain, M. S. Paterson, The effect of hydrostatic pressure on brittleness in chromium, The Philosophical Magazine: A Journal of Theoretical Experimental and Applied Physics 9 (101) (1963) 803-815.

[23] M. Yajima, M. Ishii, M. Kobayashi, The effects of hydrostatic pressure on the ductility of metals and alloys, International Journal of Fracture 6 (2) (1970) 139-150.

[24] T.-Y. Kim, J. E. Dolbow, E. Fried, Numerical study of the grain-size dependent youngs modulus and poissons ratio of bulk nanocrystalline materials, International Journal of Solids and Structures 49 (26) (2012) $3942-3952$

[25] The effects of grain size and porosity on the elastic modulus of nanocrystalline materials, Nanostructured Materials 11 (3) (1999) $361-367$.

[26] Effect of grain size on the elastic properties of nanocrystalline alpha-iron, Scripta Materialia 48 (5) (2003) 611 -615 .

[27] R. Mohsen, P. Zeng, W. Rainforth, Correlation of the wear transition in cocrmo alloys with the formation of a nanocrystalline surface layer and a proteinaceous surface film 376-377 (2017) 223-231.

[28] R. Bscher, G. Tger, W. Dudzinski, B. Gleising, M. Wimmer, A. Fischer, Subsurface microstructure of metal-on-metal hip joints and its relationship to wear particle generation, Journal of Biomedical Materials Research Part B: Applied Biomaterials 72B (1) 206214.

[29] R. Ahmed, H. L. D. Lovelock, S. Davies, N. H. Faisal, Influence of re-hiping on the structure-property relationships of cobalt-based alloys, Tribology International 57 (2013) 8-21.

[30] A. Frenk, J. D. Wagniere, Laser cladding with cobaltbased hardfacing alloys, Journal De Physique Iv 1 (C7) (1991) 65-68.

[31] H. So, C. T. Chen, Y. A. Chen, Wear behaviours of 